Check for updates

Cite this: RSC Adv., 2018, 8, 38204

Received 30th July 2018

Accepted 4th November 2018

DOI: $10.1039 / \mathrm{c} 8 \mathrm{ra06426a}$

rsc.li/rsc-advances

\section{Chemical state changes of Nafion in model polymer electrolyte fuel cell under oxygen/hydrogen gas atmosphere observed by S-K XANES spectroscopy $\uparrow$}

\begin{abstract}
Kazuhisa Isegawa, Daehyun Kim and Hiroshi Kondoh (D) *
Changes in the chemical states of the sulfonic groups of Nafion in a model polymer electrolyte fuel cell under an oxygen/hydrogen gas atmosphere were studied using sulfur K-edge XANES spectroscopy. First, the chemical state changes in the sulfonic acid groups of both cathode and anode electrodes due to humidity under oxygen/hydrogen gas flow were observed. Reversible spectral changes ascribed to the hydration and dehydration of the sulfonic acid group were observed at both electrodes. This result is similar to the experimental results obtained without introducing oxygen (helium/hydrogen). On the anode, some of the sulfonic acid groups were decomposed to atomic sulfur adsorbed on platinum $\left(S_{a d}\right)$ and the amount increased with time. On the cathode, the formation of $S_{a d}$ was suppressed under the oxygen atmosphere. Next, the effects of oxygen gas introduction onto $S_{a d}$ were examined. $S_{a d}$ was at once formed on both electrodes under dry conditions without an oxygen supply. By supplying oxygen gas, $\mathrm{S}_{\mathrm{ad}}$ on the cathode disappears. Therefore, the catalyst of the cathode has the ability to recover against the poisoning $S_{a d}$, while that on the anode accumulates.
\end{abstract}

\section{Introduction}

A prototype of fuel cells was developed by W. R. Grove in $1839 .^{1}$ A century later, fuel cells were adopted as a power source for spacecraft and are nowadays used for green energy whose emission consists only of water. Among several types of fuel cells, polymer electrolyte fuel cells (PEFCs), which are used for fuel cell vehicles, home generators and so on, have been extensively studied to understand their working mechanisms as well as to improve their efficiency and durability. PEFCs are typically composed of carbon-supported platinum catalysts and polyelectrolytes. Nafion has been often used as a polyelectrolyte, consisting of a hydrophobic polytetrafluoroethylene (PTFE) backbone and hydrophilic side chains with sulfonic acid groups. The advantages of PEFCs are a solid electrolyte and low temperature operation. On the other hand, both the platinum catalyst and Nafion deteriorate easily and the power generation efficiency is lower than that of other types of fuel cells.

Since proton transfer by Nafion is one of the key points of PEFCs, the hydration of the sulfonic acid groups ${ }^{2-5}$ and the interaction between Nafion and platinum ${ }^{6-12}$ have been investigated by various methods. In addition, it is known that

Department of Chemistry, Keio University, 3-14-1 Hiyoshi, Kohoku-Ku, Yokohama, 223-8522 Japan. E-mail: kondoh@chem.keio.ac.jp

$\dagger$ Electronic supplementary information (ESI) available: Cyclic voltammetry curves for the MEAs depending on humidity, open circuit voltage changes due to humidity and temperature, and peak analysis of low-energy region of the S-K XANES spectra. See DOI: 10.1039/c8ra06426a a structure composed of a platinum catalyst, a carbon support and Nafion affects the performance and lifespan of PEFCs. ${ }^{13-19}$

The deterioration process of PEFCs is also important. Research combining electron microscopy and Pt-L EXAFS revealed the degradation processes of the platinum fine particle catalyst, such as dissolution, detachment, carbon corrosion and so on. ${ }^{20-24}$ Both the main chain and the side chain of Nafion are decomposed by hydroxyl radicals, which are generated by the decomposition of hydrogen peroxide arising from cross-leaked fuel gas on the platinum catalyst. ${ }^{25,26}$ The decomposition reaction is accelerated by the progress of decomposition, ${ }^{27}$ drying, ${ }^{28}$ over-humidification $^{29}$ and high pressure. ${ }^{30}$ Contrary to the consensus, there is a report that the platinum catalyst detoxifies hydrogen peroxide and inhibits the decomposition of Nafion. ${ }^{31}$ It is also noted that Nafion is easily destroyed by exposure to radiation such as $\gamma$ rays, $\beta$ rays, ${ }^{32-36}$ XAFS measurement, ${ }^{37}$ XPS measurement ${ }^{38}$ and EELS measurement. ${ }^{39}$

X-ray absorption fine structure spectroscopy (XAFS: further divided into XANES and EXAFS depending on the energy region) enables us to carry out element-selective observations of chemical states and local structures. Changes in the chemical state of a noble metal catalyst due to potential have been reported in detail by time resolved Pt- $\mathrm{L}_{\mathrm{m}}$ EXAFS. ${ }^{40,41}$ It is reported that C-K ELNES (energy loss near edge spectroscopy) reflects sensitively the helical structure of the main chain of Nafion. ${ }^{\mathbf{4 2 , 4 3}}$ ELNES is a core-level spectroscopy similar to XANES and has better light element detectability and spatial resolution capability. Research on fuel cells using S-K XANES has clarified the effect of sulfur dioxide in air on the catalyst. ${ }^{\mathbf{4 4 , 4 5}}$ However, this 
study did not necessarily focus on the sulfonic acid groups of Nafion. Therefore, previously we tried S-K XANES measurements of PEFC under $\mathrm{He} / \mathrm{H}_{2}$ gas-flow and revealed that this technique gives information on the hydration of sulfonic acid groups and the formation of atomic sulfur adsorbed on platinum under dry condition. ${ }^{37}$

In this paper, we conducted an S-K XANES study on changes in the chemical state of the sulfonic acid groups of Nafion in a model PEFC under oxygen atmosphere. First, the influence of oxygen gas due to humidity on the changes in the chemical state of a sulfonic acid group was investigated. Next, XANES observations were conducted under the introduction to atomic sulfur adsorbed on platinum of oxygen which is produced under dry conditions. The chemical state of Nafion on the anode electrode was also analysed under each condition. Since water emitted by power generation absorbs and scatters $\mathrm{X}$ rays significantly and inhibits the drying of the catalyst, we investigated the effects of oxygen gas and of dry conditions on Nafion without a flowing electric current.

\section{Experimental}

\section{Soft X-ray near in situ electrochemical XAFS system}

The experimental setup is shown in our previous paper. ${ }^{37}$ The apparatus was modified to supply a mixed gas of helium and oxygen.

The fuel cell used here has a multilayer structure, as shown in Fig. 1. Membrane electrode assemblies (MEAs) consisting of Nafion-212 and $50 \mathrm{wt} \% \mathrm{Pt} / \mathrm{C}$ (Vulcan XC-72) $\left(1 \mathrm{mg}_{\mathrm{Pt}} \mathrm{cm}^{-2}\right.$ ) (ElectroChem Inc., USA) were peeled off a gas diffusion layer (GDL) on the cathode side and loaded into the fuel cell. Each layer was electrically connected by fixing with insulated screws. For the anode electrode, hydrogen gas was supplied onto the MEA through a GDL, which can be used to define the potential of the catalyst. The cathode electrode has a conical hole for passing X rays, and the fuel gases are supplied from the hole without GDL. The conical hole is capped by a PET film (thickness of $6 \mu \mathrm{m}$ ) to seal the flow gas from the He-path. Since the

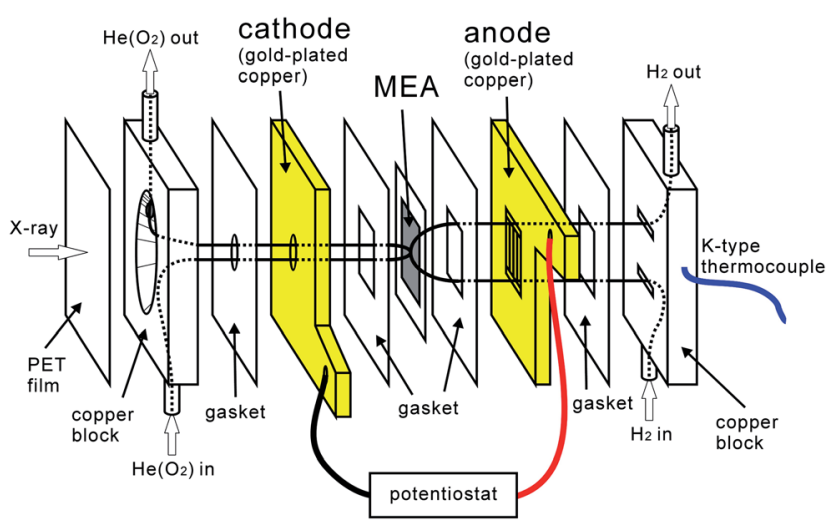

Fig. 1 Structure of the fuel cell for in situ XANES measurements. The figure shows the setup for XANES measurement of the cathode; the anode and the cathode can be exchanged by changing the electric wiring and the gas line system. catalyst ink layer is thick enough to prevent transmission of $2500 \mathrm{eV} X$ rays through the layer, the XANES spectra from one electrode are not influenced by the contribution from the polymer electrolyte or from another electrode. The electrodes are floating electrically from the chamber by the insulation between the metal plates connected to the gas line and the electrodes so that the anode and the cathode can be exchanged by changing the electric wiring and the gas line system.

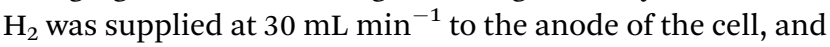

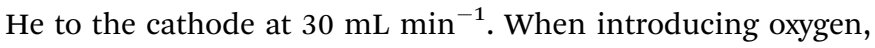
$\mathrm{O}_{2}-\mathrm{He}$ mixed gas $\left(\mathrm{O}_{2}: \mathrm{He}=1: 4\right)$ was supplied to the cathode at $30 \mathrm{~mL} \mathrm{~min}^{-1}$. The humidity of the cell was defined by the dew point of the supplied fuel gases and the temperature of the cell. The temperature of the cell was measured by a thermocouple attached to the gas introduction block (Fig. 1). Under wet conditions, the flow gases passed through bubblers at room temperature and the fuel cell was also at room temperature, which results in a dew point of $26^{\circ} \mathrm{C}$. The humidity under these gas conditions was $30-70 \%$ depending on the cell temperature. Under dry conditions, the gases were supplied without bubblers and the fuel cell was heated to $55^{\circ} \mathrm{C}\left(-40^{\circ} \mathrm{CDP}, \mathrm{RH} 0 \%\right)$. The MEA tends to swell with water and cross-leakage of the fuel gases occurs, which could be induced by the conical hole of the cathode electrode for X-ray introduction. The humidity of the wet conditions was set slightly lower in order to prevent the catalysts from burning due to the cross-leakage. A potentiostat/ galvanostat (Hokuto Denko corp. HA-151B) was used for electrochemical measurements.

\section{XANES measurements}

Sulfur K-edge XANES spectra were measured in the fluorescence mode using a silicon drift detector (XR-100SDD, Amptek) at beam line 11B of the Photon-Factory of High Energy Accelerator Research Organization (KEK-PF) in Tsukuba, Japan. Sulfur powder (S, 99.9999\%, Wako Pure Chemical Industries, Ltd) and an aqueous solution of sulfuric acid $\left(\mathrm{H}_{2} \mathrm{SO}_{4}, 96.0 \%\right.$, Kanto Chemical Co., Inc.) were used as the standard substances to calibrate the sulfur K-edge energy (sulfur powder: $2472.4 \mathrm{eV}$, sulfuric acid: $2482.1 \mathrm{eV}$ ). ${ }^{44}$ The aqueous solution of $\mathrm{H}_{2} \mathrm{SO}_{4}$ was adjusted to $0.1 \mathrm{M}$ and sealed in polypropylene films.

Since we found in the previous study that intense $\mathrm{X}$ rays decompose Nafion into sulfuric acid, ${ }^{37}$ polyethylene membranes were properly installed on the X-ray path in order to reduce the X-ray intensity.

\section{Result and discussion}

\section{Effects of humidity change under oxygen atmosphere}

S-K XANES spectra of model PEFCs measured under oxygen gasflow are shown in Fig. 2. For observation of the anode shown in Fig. 2A, hydrogen was supplied to the electrode with the conical hole for X-ray irradiation and helium (and oxygen) was supplied to another electrode. While for observation of the cathode shown in Fig. 2B, the supplied gases were exchanged with each other. All the spectra were normalized by the intensity of the post-edge region. 


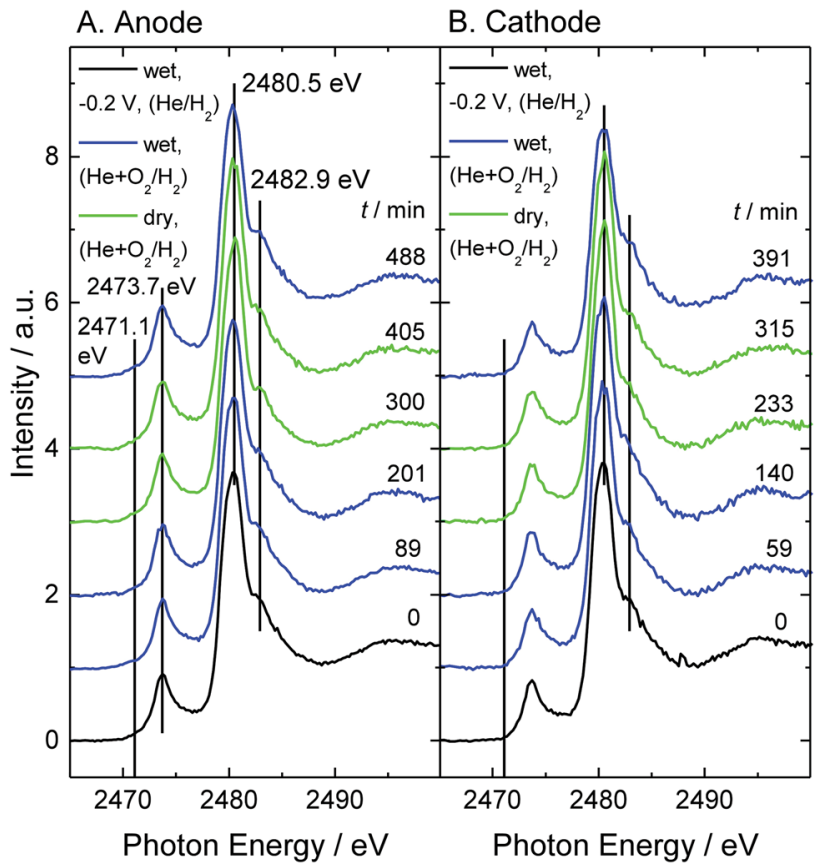

Fig. 2 S-K XANES spectra of model PEFC under gas-flow conditions: (A) anode side, (B) cathode side. Initial spectra (black) were measured at a cathode voltage of $-0.2 \mathrm{~V}$ vs. SHE under wet $\mathrm{He} / \mathrm{H}_{2}$ gas-flow $(\mathrm{RH}$ $70 \%)$. Blue spectra were taken under wet $\mathrm{He}+\mathrm{O}_{2} / \mathrm{H}_{2}$ gas-flow $(\mathrm{RH}$ $70 \%)$. Green spectra were taken under dry $\mathrm{He}+\mathrm{O}_{2} / \mathrm{H}_{2}$ gas-flow (RH $0 \%)$. The relative humidity for the last blue spectrum taken during recovery from the dry condition (green spectra) was $\mathrm{RH} 37 \%$. The ratio of oxygen and helium is $1: 4$. The elapsed time from the initial measurement is shown on the right-hand side. The vertical lines indicate atomic sulfur adsorbed on platinum $\left(\mathrm{S}_{\mathrm{ad}}\right)(2471.1 \mathrm{eV})$, impurity thioether $(2473.7 \mathrm{eV})$, the main peak $(2480.5 \mathrm{eV})$ and the shoulder structure $(2482.9 \mathrm{eV})$.

First, at $-0.2 \mathrm{~V}$ under wet helium/hydrogen gas-flow ( $\mathrm{RH}$ $70 \%$ ), the break-in operation was performed and the reference S-K XANES spectra (black lines) and cyclic voltammetry (Fig. S1†) were measured for a performance test. Next, under oxygen gas-flow, the effects of humidity change on the S-K XANES spectra were investigated. Changes in cell temperature and open circuit voltage are shown in Fig. S3. $\uparrow$ Nafion exhibits a main peak at $2480.5 \mathrm{eV}$ and a shoulder structure at $2482.9 \mathrm{eV}$. A large peak that appears at $2473.7 \mathrm{eV}$ in the pre-edge region is attributed to the thioether group (2473.1-2474.3 eV). ${ }^{46,47}$ This peak is not detected in the S-K XANES spectrum of a pristine Nafion-212 membrane ${ }^{44,45}$ but is exclusively observed for $\mathrm{Pt} / \mathrm{C}$ catalysts. Therefore, this sulfur species is assumed to be included in the carbon support, Vulcan XC-72. Since modification of the carbon support with sulfonic acid or amine affects the performance of fuel cells, ${ }^{17,19}$ this sulfur species may have some effect on the activity. The thioether peak seems to be large relative to the sulfonic acid peaks. However, assuming the ion exchange capacity to be almost $1 \mathrm{mEq} \mathrm{g}^{-1}$ and the ionomer/ carbon ratio to be 1.0 or less, the molar fraction of the sulfur impurity in the carbon support is estimated to be less than $1 \%$.

The spectral shape and peak position in Fig. 2 seem to be maintained against changes in humidity and supplied gas. So, the intensity ratio of the main peak $(2480.5 \mathrm{eV})$ and the shoulder structure $(2482.9 \mathrm{eV})$ are plotted as a function of elapsed time (Fig. 3). The ratio became smaller exclusively under dry conditions, which is the same as the results without an oxygen gas supply. ${ }^{37}$ According to the density functional theory transitionpotential (DFT-TP) calculation ${ }^{48}$ of the S-K XANES of fluoroalkylsulfonic acid, the main peak is attributed to excitation from the $\mathrm{S} 1 \mathrm{~s}$ level into the antibonding $\sigma^{*}(\mathrm{~S}-\mathrm{C})$ molecular orbital and the shoulder structure is attributed to excitation to the antibonding $\pi^{*}(\mathrm{~S}-\mathrm{C})$ molecular orbital. ${ }^{49}$ Three bonds between sulfur and oxygen could not be easily named because of the mixing of $\sigma^{*}$ and $\pi^{*}$ molecular orbitals. By combining experiments and DFT-TP calculations, we revealed that the intensity ratio of the main peak and the shoulder structure reflects the adsorption and desorption of a proton to/from the sulfonic acid group. ${ }^{37}$ Similar intensity changes were observed for the interaction between sulfonic acid groups and vanadium ions. ${ }^{50}$

Our previous study revealed that the sulfonic acid group is decomposed into atomic sulfur adsorbed on the platinum electrode $\left(S_{\mathrm{ad}}\right)$ on the cathode under the condition of dry helium gas-flow irrespective of the X-ray irradiation time. ${ }^{37}$ Although it is presumed that the sulfonic acid groups losing the coordination water are pulled to the platinum catalyst under dry conditions, ${ }^{51}$ the detailed decomposition mechanism is still unclear. The intensity of $S_{\text {ad }}(2471.1 \mathrm{eV})^{44,45}$ in the spectra of Fig. 2 is plotted as shown in Fig. 4. $S_{\text {ad }}$ gradually increases on the anode, while it is much lower on the cathode. In this study, it is possible that not only sulfonic acid in Nafion but also the sulfurcontaining species observed at $2473.7 \mathrm{eV}$ (thioether in the carbon support) is a source of sulfur species for the generation of $\mathrm{S}_{\mathrm{ad}}$. However, thioether in the carbon support is not involved in the production of $S_{a d}$ because the intensity change in $S_{a d}$ is independent of that of thioether. Details are discussed in Section 3 of the ESI. $\dagger$

Enlarged views of the pre-edge region of the spectra in Fig. 2 are shown in Fig. S5. $\dagger$ For the anode, the spectral curves appear to be convex upward at $2471.1 \mathrm{eV}$ even in the first spectrum, while for the cathode, the spectra remain convex downward under any conditions. This means that, on the anode, the sulfonic acid group decomposes not only under dry conditions but also with the supply of hydrogen gas. Comparing A and B in

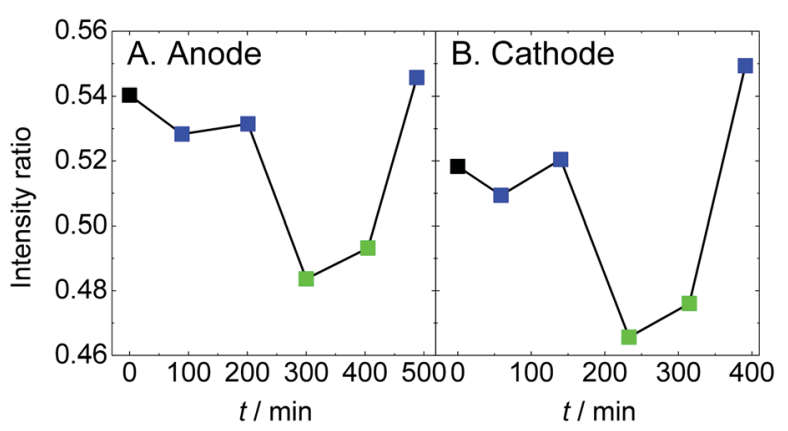

Fig. 3 The intensity ratio averaged over 5 points of the main peak $(2480.5 \mathrm{eV})$ and the shoulder structure $(2482.9 \mathrm{eV})$ in the spectra shown in Fig. 2 are plotted as a function of elapsed time. The color code is the same as that in Fig. 2. 


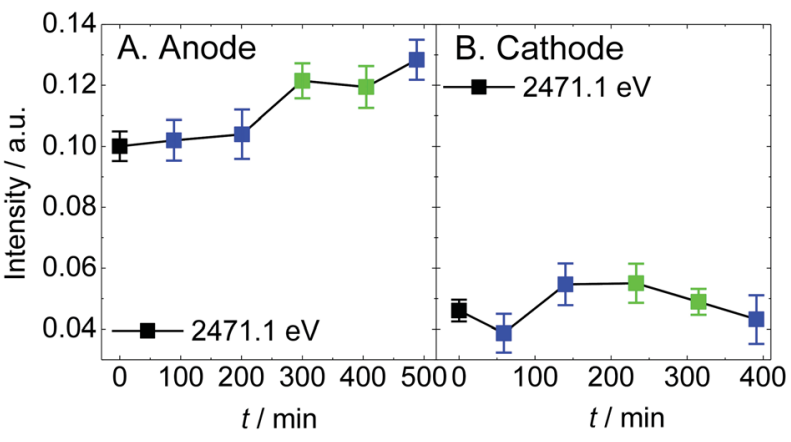

Fig. 4 The intensity averaged over 5 points around $2471.1 \mathrm{eV}$ in the spectra shown in Fig. 2 are plotted as a function of elapsed time. The color code is the same as that in Fig. 2.

Fig. 4, the intensity of $S_{a d}$ on the anode during the break-in operation under hydrogen gas becomes larger by about 0.05 arb. units than that on the cathode and an additional 0.03 arb. units was generated during 8 hours of experiment. 1 arb. unit corresponds to the total amount of all kinds of sulfur species of the sample. On the anode, it is suggested that the sulfonic acid groups are reduced by hydrogen on the platinum catalyst regardless of humidity. Although the catalyst and Nafion deteriorate by only a trace amount during 8 hours of experiment, this will have a non-negligible negative effect in a long-term experiment. On the other hand, $\mathrm{S}_{\mathrm{ad}}$ on the cathode does not increase. The generation of sulfur species is suppressed under oxygen atmosphere at $1 \mathrm{~V}$ (open circuit voltage).

\section{Effects of oxygen gas on atomic sulfur adsorbed on platinum}

In the previous section, we found the generation of sulfur on the catalyst under $\mathrm{He}+\mathrm{O}_{2} / \mathrm{H}_{2}$ gas-flow conditions. In this section, we intentionally generated $\mathrm{S}_{\mathrm{ad}}$ on both electrodes by dry treatment and subsequently attempted to clarify the behaviour of the once-generated sulfur under $\mathrm{He}+\mathrm{O}_{2} / \mathrm{H}_{2}$ gas-flow conditions. A series of spectra are shown in Fig. 5. First, the break-in operation was performed at $-0.2 \mathrm{~V}$ under wet helium/hydrogen gas-flow conditions (black lines (RH 70\%)). Next, the dried gases were supplied for 9 hours to generate $\mathrm{S}_{\mathrm{ad}}$ (red lines (RH $\left.0 \%\right)$ ). After that, a mixed gas of oxygen and helium $(1: 4)$, which was initially dry and then moistened afterwards, was supplied to the cathode (green (RH 0\%) and blue lines (RH 30\%)). Cyclic voltammograms were measured at each condition (Fig. S2 †). Changes in cell temperature and open circuit voltage are shown in Fig. S4. $\dagger$

The intensity ratio of the main peak and the shoulder structure and the intensity of $S_{\text {ad }}$ are plotted as a function of elapsed time, as shown in Fig. 6 and 7, respectively. The $S_{a d}$ species increase at both electrodes under the dry helium/ hydrogen gas-flow conditions. On the anode, $\mathrm{S}_{\mathrm{ad}}$ increases steadily under a reducing atmosphere irrespective of humidity. On the other hand, exposing oxygen gas onto the cathode gives rise to a drastic decrease in $S_{a d}$. This result suggests that $S_{a d}$ is removed from the platinum surface via oxidation. Thus the platinum catalyst on the cathode can be regenerated under wet oxygen gas-flow even if it is contaminated by sulfur under overly

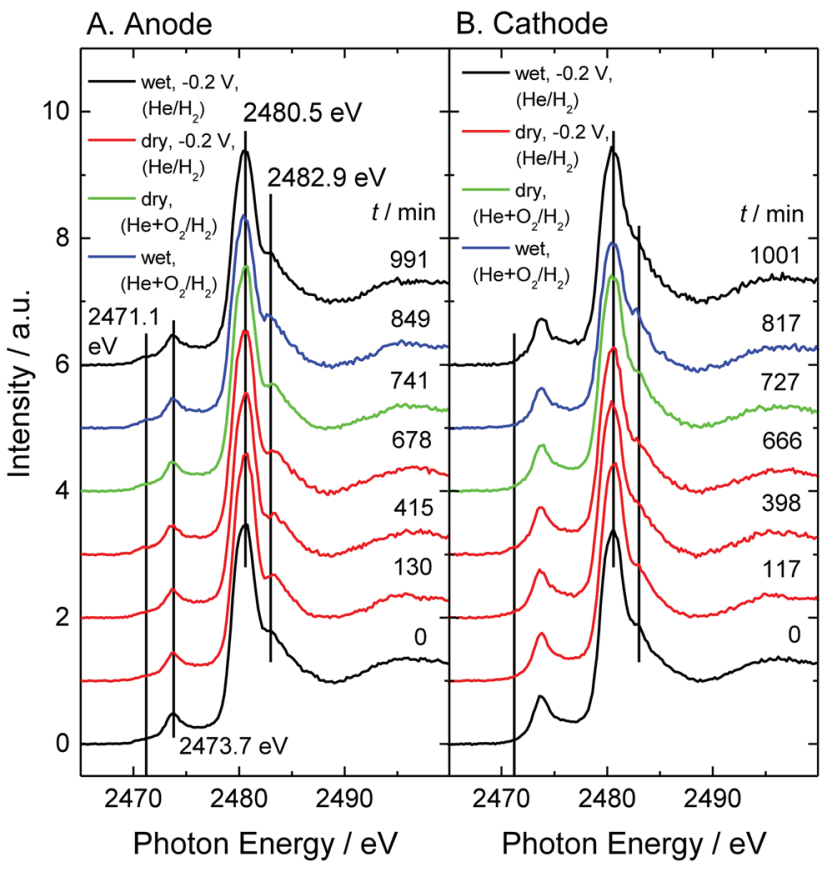

Fig. 5 S-K XANES spectra of model PEFC under gas-flow conditions: (A) anode side, (B) cathode side. Initial spectra (bottom: black) were measured at a cathode voltage of $-0.2 \mathrm{~V}$ vs. SHE under wet $\mathrm{He} / \mathrm{H}_{2}$ gas-flow ( $\mathrm{RH} 70 \%)$. The following red-colored spectra were taken at $-0.2 \mathrm{~V}$ under dry $\mathrm{He} / \mathrm{H}_{2}$ gas-flow $(\mathrm{RH} 0 \%)$. Green spectra were taken under dry $\mathrm{He}+\mathrm{O}_{2} / \mathrm{H}_{2}$ gas-flow ( $\mathrm{RH} 0 \%$ ). Blue spectra were taken under wet $\mathrm{He}+\mathrm{O}_{2} / \mathrm{H}_{2}$ gas-flow during recovery from the dry conditions (green spectra) ( $\mathrm{RH} 30 \%)$. The relative humidity for the last black spectrum was $\mathrm{RH} 35 \%$. The ratio of oxygen and helium is $1: 4$. The elapsed time from the initial measurement is shown on the right-hand side. The vertical lines indicate atomic sulfur adsorbed on platinum $\left(\mathrm{S}_{\mathrm{ad}}\right)(2471.1 \mathrm{eV})$, impurity thioether $(2473.7 \mathrm{eV})$, the main peak (2480.6 $\mathrm{eV})$ and the shoulder structure $(2483.0 \mathrm{eV})$.

dry conditions or $\mathrm{SO}_{2}$ gas-flow. ${ }^{\mathbf{4 4 , 4 5}}$ However, the conduction of MEAs was not completely recovered, as shown in Fig. S2, $\dagger$ because of the irreversible decomposition of Nafion and the increase in $\mathrm{S}_{\mathrm{ad}}$ on the anode electrode. Although the deterioration of the cathode catalysts has been paid much attention so far, the present experiment under gas-flow reveals renewed deterioration pathways relating to the anode catalysts as well as to the electrolyte.
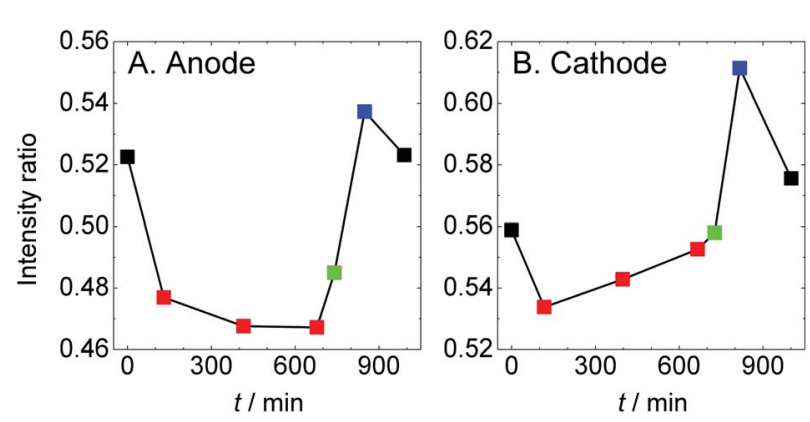

Fig. 6 The intensity ratio averaged over 5 points of the main peak $(2480.6 \mathrm{eV})$ and the shoulder structure $(2483.0 \mathrm{eV})$ in the spectra shown in Fig. 5 are plotted as a function of elapsed time. The color code is the same as that in Fig. 5. 


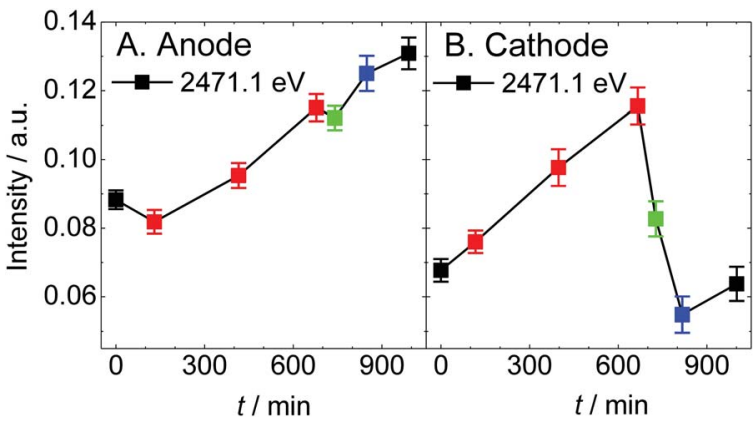

Fig. 7 The intensity averaged over 5 points around $2471.1 \mathrm{eV}$ in the spectra shown in Fig. 5 are plotted as a function of elapsed time. The color code is the same as that in Fig. 5.

\section{Conclusions}

We developed a model fuel cell electrically insulated from the gas line and used it for a soft X-ray electrochemical XAFS system. First, we investigated the chemical state of Nafion under an $\mathrm{He}+\mathrm{O}_{2}$ (cathode) $/ \mathrm{H}_{2}$ (anode) atmosphere by $\mathrm{S}-\mathrm{K}$ XANES. We observed the hydration/dehydration of the sulfonic acid group due to humidity change and sulfur poisoning of the platinum catalyst on the anode. Next, we examined the effects of introduction of oxygen gas on the poisoning sulfur. After supplying the $\mathrm{He}+\mathrm{O}_{2} / \mathrm{H}_{2}$ gas, the generated $\mathrm{S}_{\mathrm{ad}}$ species on the cathode significantly decrease. This indicates that the cathode has regenerative capability against sulfur contamination on the platinum catalyst. Whereas on the anode the sulfur accumulates.

\section{Conflicts of interest}

There are no conflicts of interest to declare.

\section{Acknowledgements}

This study was supported by the research fund from Keio University and the Grants-in-Aid for scientific research (18K19064). The experiments have been performed under the approval of the Photon Factory Program Advisory Committee (PF PAC No. 2015G601).

\section{References}

1 W. R. Grove, Philos. Mag., 1839, 14, 127-130.

2 K. Kunimatsu, B. Bae, K. Miyatake, H. Uchida and M. Watanabe, J. Phys. Chem. B, 2011, 115, 4315-4321.

3 C. Wakai, T. Shimoaka and T. Hasegawa, Anal. Chem., 2013, 85, 7581-7587.

4 T. Shimoaka, C. Wakai, T. Sakabe, S. Yamazaki and

T. Hasegawa, Phys. Chem. Chem. Phys., 2015, 17, 8843-8849.

5 Y. Cui, Y. Harada, T. Hatanaka, N. Nakamura, M. Ando,

T. Yoshida, E. Ikenaga, K. Ishii, D. Matsumura, R. Li and M. Oshima, ECS Trans., 2016, 72(8), 131-136.
6 R. Subbaraman, D. Strmcnik, V. Stamenkovic and N. M. Markovic, J. Phys. Chem. C, 2010, 114, 8414-8422.

7 I. Kendrick, D. Kumari, A. Yakaboski, N. Dimakis and E. S. Smotkin, J. Am. Chem. Soc., 2010, 132, 17611-17616.

8 M. Ahmed, D. Morgan, G. A. Attard, E. Wright, D. Thompsett and J. Sharman, J. Phys. Chem. C, 2011, 115, 17020-17027.

9 H. Hanawa, K. Kunimatsu, M. Watanabe and H. Uchida, J. Phys. Chem. C, 2012, 116, 21401-21406.

10 T. Masuda, K. Ikeda and K. Uosaki, Langmuir, 2013, 29, 2420-2426.

11 T. Masuda, F. Sonsudin, P. R. Singh, H. Naohara and K. Uosaki, J. Phys. Chem. C, 2013, 117, 15704-15709.

12 T. Masuda, H. Fukumitsu, T. Kondo, H. Naohara, K. Tamura, O. Sakata and K. Uosaki, J. Phys. Chem. C, 2013, 117, 1216812171.

13 R. Subbaraman, D. Strmcnik, A. P. Paulikas, V. R. Stamenkovic and N. M. Markovic, ChemPhysChem, 2010, 11, 2825-2833.

14 R. Lin, T. Zhao, M. Shang, J. Wang, W. Tang, V. E. Guterman and J. Ma, J. Power Sources, 2015, 293, 274-282.

15 S. M. Andersen, R. Dhiman, M. J. Larsen and E. Skou, Appl. Catal., B, 2015, 172-173, 82-90.

16 J. Chlistunoff and B. Pivovar, J. Electrochem. Soc., 2015, 162(8), F890-F900.

17 S. M. Andersen, Appl. Catal., B, 2016, 181, 146-155.

18 T. Kim, J. Yi, C. Jung, E. Jeong and S. Yi, Int. J. Hydrogen Energy, 2017, 42, 478-485.

19 F. Yang, L. Xin, A. Uzunoglu, Y. Qiu, L. Stanciu, J. Ilavsky, W. Li and J. Xie, ACS Appl. Mater. Interfaces, 2017, 9, 65306538.

20 J. C. Meier, C. Galeano, I. Katsounaros, A. A. Topalov, A. Kostka, F. Schüth and K. J. J. Mayrhofer, ACS Catal., 2012, 2, 832-843.

$21 \mathrm{H}$. Yoshida, T. Kinumoto, Y. Iriyama, Y. Uchimoto and Z. Ogumi, ECS Trans., 2007, 11(1), 1321-1329.

22 Y. Yu, H. L. Xin, R. Hovden, D. Wang, E. D. Rus, J. A. Mundy, D. A. Muller and H. D. Abruña, Nano Lett., 2012, 12, 44174423.

23 O. A. Baturina, A. Epshteyn, P. Northrup and K. E. SwiderLyons, J. Electrochem. Soc., 2014, 161(4), F365-F372.

24 J. A. Gilbert, A. J. Kropf, N. N. Kariuki, S. DeCrane, X. Wang, S. Rasouli, K. Yu, P. J. Ferreira, D. Morgan and D. J. Myers, J. Electrochem. Soc., 2015, $162(14)$, F1487-F1497.

25 L. Ghassemzadeh, K.-D. Kreuer, J. Maier and K. J. Müller, J. Phys. Chem. C, 2010, 114, 14635-14645.

26 T. Kinumoto, M. Inaba, Y. Nakayama, K. Ogata, R. Umebayashi, A. Tasaka, Y. Iriyama, T. Abe and Z. Ogumi, J. Power Sources, 2006, 158, 1222-1228.

27 K. Ono, Y. Yasuda, K. Sekizawa, N. Takeuchi, T. Yoshida and M. Sudoh, Electrochim. Acta, 2013, 97, 58-65.

28 M. Inaba, T. Kinumoto, M. Kiriake, R. Umebayashi, A. Tasaka and Z. Ogumi, Electrochim. Acta, 2006, 51, 57465753.

29 D. G. Sanchez, T. Ruiu, I. Biswas, M. Schulze, S. Helmly and K. A. Friedrich, J. Power Sources, 2017, 352, 42-55.

30 A. Kusoglu, M. Calabrese and A. Z. Weber, ECS Electrochem. Lett., 2014, 3(5), F33-F36. 
31 M. Bodner, B. Cermenek, M. Rami and V. Hacker, Membranes, 2015, 5, 888-902.

32 Y. Iwai, T. Yamanishi, M. Nishi, T. Yagi and M. Tamada, J. Nucl. Sci. Technol., 2005, 42, 636-642.

33 Y. Iwai, A. Hiroki, M. Tamada and T. Yamanishi, J. Membr. Sci., 2008, 322, 249-255.

34 Y. Iwai, A. Hiroki, M. Tamada, K. Isobe and T. Yamanishi, Radiat. Phys. Chem., 2010, 79, 46-51.

35 Y. Iwai, A. Hiroki and M. Tamada, J. Membr. Sci., 2011, 369, 397-403.

36 Y. Iwai, K. Sato and T. Yamanishi, Fusion Eng. Des., 2014, 89, 1534-1538.

37 K. Isegawa, T. Nagami, S. Jomori, M. Yoshida and H. Kondoh, Phys. Chem. Chem. Phys., 2016, 18, 25183-25190.

38 M. Schulze, M. Lorenz, N. Wagner and E. Gülzow, Fresenius. J. Anal. Chem., 1999, 365, 106-113.

39 Q. He, J. Chen, D. J. Keffer and D. C. Joy, Scanning, 2014, 36, 338-346.

40 M. Tada, S. Murata, T. Asakoka, K. Hiroshima, K. Okumura, H. Tanida, T. Uruga, H. Nakanishi, S. Matsumoto, Y. Inada, M. Nomura and Y. Iwasawa, Angew. Chem., Int. Ed., 2007, 46, 4310-4315.

41 O. Sekizawa, T. Uruga, K. Higashi, T. Kaneko, Y. Yoshida, T. Sakata and Y. Iwasawa, ACS Sustainable Chem. Eng., 2017, 5, 3631-3636.

42 C. Wang, G. Duscher and S. J. Paddison, Microscopy, 2014, 63(1), 73-83.
43 C. Wang, G. Duscher and S. J. Paddison, RSC Adv., 2015, 5, 2368-2373.

44 O. A. Baturina, B. D. Gould, A. Korovina, Y. Garsany, R. Stroman and P. A. Northrup, Langmuir, 2011, 27, 1493014939.

45 O. A. Baturina, B. D. Gould, P. A. Northrup and K. E. SwiderLyons, Catal. Today, 2013, 205, 106-110.

46 J. Prietzel, J. Thieme, U. Neuhäusler, J. Ssusini and I. KögelKnabner, Eur. J. Soil Sci., 2003, 54, 423-433.

47 F.-R. Orthous-Daunay, E. Quirico, L. Lemelle, P. Beck, V. deAndrade, A. Simionovici and S. Derenne, Earth Planet. Sci. Lett., 2010, 300, 321-328.

48 K. Hermann, L. G. M. Pettersson, M. E. Casida, C. Daul, A. Goursot, A. Koester, E. Proynov, A. St-Amant and D. R. Salahub. Contributing authors: V. Carravetta, H. Duarte, C. Friedrich, N. Godbout, M. Gruber, J. Guan, C. Jamorski, M. Leboeuf, M. Leetmaa, M. Nyberg, S. Patchkovskii, L. Pedocchi, F. Sim, L. Triguero and A. Vela, StoBe-deMon version 3.3, 2014.

49 E. D. Risberg, L. Eriksson, J. Mink, L. G. M. Pettersson, M. Yu. Skripkin and M. Sandströlm, Inorg. Chem., 2007, 46, 8332-8348.

50 M. Vijayakumar, N. Govind, B. Li, X. Wei, Z. Nie, S. Thevuthasan, V. Sprenkle and W. Wang, Front. Energy Res., 2015, 3, 10.

51 K. Kodama, R. Jinnouchi, T. Suzuki, H. Murata, T. Hatanaka and Y. Morimoto, Electrochem. Commun., 2013, 36, 26-28. 